\title{
A Higher Tidal Volume May Be Used for Athletes according to Measured FVC
}

\author{
Pavlos Myrianthefs and George Baltopoulos \\ Faculty of Nursing, University of Athens, ICU at Agioi Anargyroi General Hospital, Nea Kifisia, 14561 Athens, Greece \\ Correspondence should be addressed to Pavlos Myrianthefs; pmiriant@nurs.uoa.gr
}

Received 20 August 2013; Accepted 12 September 2013

Academic Editors: L. Bentur and A. Favaretto

Copyright (c) 2013 P. Myrianthefs and G. Baltopoulos. This is an open access article distributed under the Creative Commons Attribution License, which permits unrestricted use, distribution, and reproduction in any medium, provided the original work is properly cited.

\begin{abstract}
We investigated whether professional athletes may require higher tidal volume $\left(T_{v}\right)$ during mechanical ventilation hypothesizing that they have significantly higher "normal" lung volumes compared to what was predicted and to nonathletes. Measured and predicted spirometric values were recorded in both athletes and nonathletes using a Spirovit SP-1 spirometer (Schiller, Switzerland). Normal $T_{v}(6 \mathrm{~mL} / \mathrm{kg}$ of predicted body weight) was calculated as a percentage of measured and predicted forced vital capacity (FVC) and the difference $(\delta)$ was used to calculate the additional $T_{v}$ required using the equation: $\operatorname{New} T_{v}\left(T_{v} N\right)=T_{v}+\left(T_{v} \times \delta\right)$. Professional athletes had significantly higher FVC compared to what was predicted (by $9 \%$ in females and $10 \%$ in males) and to nonathletes. They may also require a $T_{v}$ of $6.6 \mathrm{~mL} / \mathrm{kg}$ for males and $6.5 \mathrm{~mL} / \mathrm{kg}$ for females during mechanical ventilation. Nonathletes may require a $T_{v}$ of $5.8 \pm 0.1 \mathrm{~mL} / \mathrm{kg}$ and $6.3 \pm 0.1 \mathrm{~mL} / \mathrm{kg}$ for males and females, respectively. Our findings show that athletes may require additional $T_{v}$ of $10 \%(0.6 / 6 \mathrm{~mL} / \mathrm{kg})$ for males and $8.3 \%(0.5 / 6 \mathrm{~mL} / \mathrm{kg})$ for females during general anesthesia and critical care which needs to be further investigated and tested.
\end{abstract}

\section{Introduction: Background}

Lung protective ventilation during the course of acute respiratory distress syndrome (ARDS) uses a tidal volume $\left(T_{v}\right)$ of $6 \mathrm{~mL} / \mathrm{kg}$ of predicted body weight [1]. This $T_{v}$ selection was associated with significant outcomes improvement in patients with ARDS [1].

This $T_{v}$ was selected because normal lung volumes are predicted on the basis of sex and height $[2,3]$. Also, this $T_{v}$ corresponds to a normal seated man at rest which is 6 to $7 \mathrm{~mL}$ per kilogram [4]. Thus, it was attempted an association between $T_{v}$ selection during mechanical ventilation and normal (predicted) lung volumes in healthy individuals at rest.

However, normal lung volumes may differ significantly between different ethnic populations and subpopulations who may have higher pulmonary function tests (PFTs) volumes including forced vital capacity (FVC) and forced expiratory volume in one second $\left(\mathrm{FEV}_{1}\right)$ than average population independently from predicted body weight. Also, it is well known that PFTs are mainly based on sex, age, height, and weight. Finally, professional athletes have higher FVC and $\mathrm{FEV}_{1}$ than what was predicted for the same body weight and thus a higher $T_{v}$ could be required to achieve "normal" $T_{v}$.

None of the studies performed until now attempted to see the effect of different PFTs values and especially the FVC in this population on tidal volume selection. To answer this question we investigated the possible effect of measured versus predicted FVC values on tidal volume selection in professional athletes.

\section{Subjects and Methods}

For the study purposes an informed consent was taken by all participants for spirometry and the study protocol was approved by Hospital Advisory Board and local Ethics Committee Board.

2.1. Study Subjects: Participants. An urban population of Greece living in Athens (70 $\mathrm{m}$ above sea level) aged 20 65 -year old were invited to participate in the study. These included students of Athens University, employees of our 
hospital and their families, and individuals visiting our outpatient clinic for checkup. Also, athletes were included from various sporting activities and spirometry was performed while visiting their facilities after communication with their trainer.

We explained the purpose of the study and the procedure of spirometry and then a clinical examination was performed based on a combination of the ECCS (European Community for Steel and Coal) standardized questionnaire on respiratory symptoms by the interviewing physician to identify eligible participants [5].

Exclusion criteria were unacceptable spirometry, previous or current smoking habit, history of chest injuries; chest, abdominal, oral, or facial pain, and presence of denture; exposure to substances known to cause lung injury; known respiratory disease (asthma, pulmonary tuberculosis, emphysema, or chronic bronchitis); respiratory symptoms during the last 12 months; hypertension; history of myocardial infarction; diabetes; dementia or confusional state; and the use of any drug and especially diuretics, cardiac glycosides, or $b$-adrenergic blocking agents [6].

Height was measured at the nearest $0.5 \mathrm{~cm}$ without shoes, in a standing position with the feet together, with the patient erect and looking straight ahead (Frankfort position). Subjects were weighted without shoes wearing indoor clothing. Age was also recorded according to birthday to the nearest 0.5 year. BMI and BSA were derived from height and weight.

2.2. Spirometry. Spirometry was performed following American Thoracic Society/European Respiratory Society (ATS/ ERS) Task Force recommendations $[5,7,8]$. All tests were performed by two physicians well educated and experienced in spirometry. Spirometry and flow/volume loops were performed using a Schiller Spirovit SP-1 spirometer (Schiller, Switzerland). This spirometer is ATS/ERS approved, fulfilling the criteria for minimal recommendations for spirometry systems and calibrated regularly [7]. Spirometry was performed in sitting position in armed chairs wearing a nose clip. Subjects were relaxed and did not smoke, exercise, consume alcohol, wear heavy clothing, or eat large meal before testing. The procedure was performed at the same room between 8.00 and 10.00 am and barometric pressure, temperature, and relative humidity were registered every morning. Hygiene and infection control measures were undertaken as recommended [7].

At least three acceptable trials were required, defined as a good start of test (extrapolated volume of $<5 \%$ of FVC or $0.15 \mathrm{~L}$, whichever was larger), at least $6 \mathrm{~s}$ of expiration and a plateau in the volume/time curve (change in volume $<30 \mathrm{~mL}$ for $\geq 2 \mathrm{~s}$ ). As recommended by the ATS, data that did not meet reproducibility criteria were not excluded, but subjects were asked to perform up to a maximum of eight manoeuvres in an attempt to obtain reproducible results. The highest $\mathrm{FEV}_{1}$ and FVC from tests of acceptable quality were used for analysis [6].

2.3. Calculations. We had four groups of data that are males and females for athletes and nonathletes, respectively.
TABLE 1: Summary statistics for males and females.

\begin{tabular}{lcc}
\hline Variable & Nonathletes & Athletes \\
\hline Males & $n=113$ & $n=156$ \\
\hline Age $($ years $)$ & $38.3 \pm 12.9$ & $26.1 \pm 0.8$ \\
Weight $(\mathrm{kg})$ & $86.1 \pm 13.2$ & $79.4 \pm 1.1$ \\
Height $(\mathrm{cm})$ & $177.7 \pm 6.6$ & $180.7 \pm 0.7$ \\
\hline Females & $n=122$ & $n=95$ \\
\hline Age $($ years $)$ & $41.7 \pm 13.9$ & $24.1 \pm 0.8$ \\
Weight $(\mathrm{kg})$ & $66.5 \pm 10.5$ & $64.1 \pm 1.0$ \\
Height $(\mathrm{cm})$ & $161.4 \pm 7.2$ & $171.7 \pm 0.8$ \\
\hline
\end{tabular}

Predicted body weight was calculated according to measured height for all participants using standard equations. For males it was calculated as equal to $50+0.91$ (centimeters of height, 152.4), and that for females was calculated as equal to $45.5+0.91$ (centimeters of height, 152.4) [1,9]. Predicted $T_{v}\left(T_{v} \operatorname{Pr}=6 \mathrm{~mL} / \mathrm{kg}\right)$ was calculated according to predicted body weight [1]. Then, predicted $T_{v}$ was then calculated as percentage of measured (Ms) and predicted $(\mathrm{Pr}) \mathrm{FVC}$ values and their difference $(\delta, \%)$ were extracted for each individual separately. This difference was used to calculate the new $T_{v}\left(T_{v} N\right)$ using the equation, New $T_{v}\left(T_{v} N\right)=T_{v}+\left(T_{v} \times \delta\right)$. New $T_{v}\left(T_{v} N\right)$ was divided to predicted body weight to calculate the corresponding $T_{v}$ per kilogram separately for each individual.

2.4. Statistics. Values are expressed as mean \pm SEM. A paired sample $t$-test was used for comparison of numerical data. A $P$ value of $<0.05$ was used to define statistical significance.

\section{Results}

Of the 550 normal individuals (nonathletes) approached 235 met the inclusion criteria and were divided according to sex which resulted in two groups of 113 males and 122 females. Also, of the 315 professional athletes 251 met the inclusion criteria and were divided according to sex which resulted in two groups of 156 males and 95 females. Summary of the study population is shown in Table 1 . Mean duration of sporting was $11.8 \pm 6.4$ and $11.6 \pm 6.9$ years for males and females, respectively. Male athletes were swimmers $(n=41)$, basketball players $(n=28)$, football players $(n=28)$, handball players $(n=13)$, athletics $(n=27)$, and gymnastic $(n=19)$. Female athletes were swimmers $(n=27)$, basketball players $(n=27)$, handball players $(n=25)$, athletics $(n=12)$, and gymnastic $(n=4)$.

Measured (Ms) and predicted (Pr) $\mathrm{FEV}_{1}$ and FVC were recorded and shown in Table 2. For nonathletes males measured $\mathrm{FEV}_{1}$ and FVC were significantly lower compared to what was predicted while for females measured FVC was significantly lower compared to what was predicted. For male and female athletes measured values were significantly higher from predicted values obtained from the ECSC prediction equation [10]. Also, in athletes measured values were approximately $9-10 \%$ higher than predicted PFTs values. The ratio (\%) of measured/predicted values in athletes and nonathletes for FVC is shown in Table 3. 
TABLE 2: Measured and predicted spirometric values $(\mathrm{mL})$.

\begin{tabular}{|c|c|c|c|}
\hline Males & Measured & Predicted & $\delta$ \\
\hline & \multicolumn{3}{|c|}{ Athletes, $n=156$} \\
\hline FVC & $5808 \pm 81.9^{*}$ & $5252 \pm 49.5^{*}$ & $+555.9 \pm 61.7$ \\
\hline $\mathrm{FEV}_{1}$ & $4831 \pm 58.9^{*}$ & $4396 \pm 40.9^{*}$ & $+434.8 \pm 45.8$ \\
\hline \multirow[t]{2}{*}{$\mathrm{FEV}_{1} / \mathrm{FVC}$} & $83.69 \pm 0.48^{*}$ & $82.07 \pm 0.12^{*}$ & $+1.6 \pm 0.47$ \\
\hline & \multicolumn{3}{|c|}{ Nonathletes, $n=113$} \\
\hline FVC & $4715 \pm 70.0^{* *}$ & $4856 \pm 53.9^{* *}$ & $-141.2 \pm 55.3$ \\
\hline $\mathrm{FEV}_{1}$ & $3876 \pm 58.4^{* *}$ & $4006 \pm 48.5^{* *}$ & $-129.9 \pm 45.2$ \\
\hline $\mathrm{FEV}_{1} / \mathrm{FVC}$ & $82.8 \pm 0.6^{*}$ & $80.6 \pm 0.2^{*}$ & $+2.2 \pm 0.6$ \\
\hline \multirow[t]{2}{*}{ Females } & Measured & Predicted & $\delta$ \\
\hline & \multicolumn{3}{|c|}{ Athletes, $n=95$} \\
\hline FVC & $4364 \pm 70.8^{*}$ & $4008 \pm 46.3^{*}$ & $+355.9 \pm 55.0$ \\
\hline $\mathrm{FEV}_{1}$ & $3757 \pm 57.3^{*}$ & $3484 \pm 40.2^{*}$ & $+273.4 \pm 45.8$ \\
\hline \multirow[t]{2}{*}{$\mathrm{FEV}_{1} / \mathrm{FVC}$} & $86.34 \pm 0.52^{*}$ & $83.73 \pm 0.09^{*}$ & $+2.6 \pm 0.50$ \\
\hline & \multicolumn{3}{|c|}{ Nonathletes, $n=122$} \\
\hline FVC & $3294 \pm 62.1^{*}$ & $3157 \pm 51.8^{*}$ & $+137.0 \pm 35.6$ \\
\hline $\mathrm{FEV}_{1}$ & $2779 \pm 54.8$ & $2717 \pm 48.2$ & $+61.9 \pm 32.9$ \\
\hline $\mathrm{FEV}_{1} / \mathrm{FVC}$ & $84.3 \pm 0.6^{*}$ & $81.6 \pm 0.2^{*}$ & $+2.7 \pm 0.6$ \\
\hline
\end{tabular}

FVC: forced vital capacity, $\mathrm{FEV}_{1}$ : forced expiratory volume in one second, m: measured, and pr: predicted according to ECSC equation. [10] ${ }^{*} P<0.0001$, ${ }^{* *} P<0.05$

TABLE 3: Ratio (\%) of measured/predicted values in athletes and nonathletes for FVC.

\begin{tabular}{lc}
\hline & FVCm/FVCpr \\
\hline Male athletes & $110.6 \pm 1.1 \%$ \\
Male nonathletes & $97.4 \pm 1.1 \%$ \\
Female athletes & $109.0 \pm 1.4 \%$ \\
Female nonathletes & $104.5 \pm 1.1 \%$ \\
\hline
\end{tabular}

FVC: forced vital capacity, m: measured, and pr: predicted.

The predicted tidal volume according to the ARDS Network $\left(T_{v} \operatorname{Pr}, 6 \mathrm{~mL} / \mathrm{kg}\right)$, the percentage to measured $(\mathrm{Ms})$ and predicted (Pr) FVC, their difference $\delta$, and the new $T_{v}\left(T_{v} N\right)$ are shown in Table 4 separately for athletes, nonathletes, males, and females.

Extracted $T_{v} N$ according to FVCm was $6.6 \pm 0.1 \mathrm{~mL} / \mathrm{kg}$ (95\% CI 6,5-6,8) for male athletes. For female athletes extracted $T_{v} N$ was $6.5 \pm 0.1 \mathrm{~mL} / \mathrm{kg}$ (95\% CI 6,4-6,7). Extracted $T_{v} N$ was $5.8 \pm 0.1 \mathrm{~mL} / \mathrm{kg}$ (95\% CI 5,7-6,0) for male nonathletes. For female nonathletes extracted $T_{v} N$ was $6.3 \pm$ $0.1 \mathrm{~mL} / \mathrm{kg}(95 \%$ CI 6,1-6,4). See also Table 4 for details. Our calculated new tidal volumes $\left(T_{v} N\right)$ were significantly higher compared to ARDS Network suggested tidal volumes (paired sample $t$-test, $P<0.0001$ ) except for male nonathletes which was significantly lower $(P \leq 0.0156)$ Figure 1.

We observed that the additional tidal volume required for male athletes was $0.6 \mathrm{~mL} / \mathrm{kg}$ which is $10 \%(0.6 \mathrm{~mL} / 6 \mathrm{~mL})$ of the suggested protective ventilation according to ARDS network. This $10 \%$ is in accordance with the $10.6 \%$ and 9.9\% higher $\mathrm{FVC}$ and $\mathrm{FEV}_{1}$, respectively found in measured values compared to predicted values as shown in Table 2 . Also, the additional tidal volume required for female athletes was $0.5 \mathrm{~mL} / \mathrm{kg}$ which is $8.3 \%(0.5 \mathrm{~mL} / 6 \mathrm{~mL})$ of the suggested

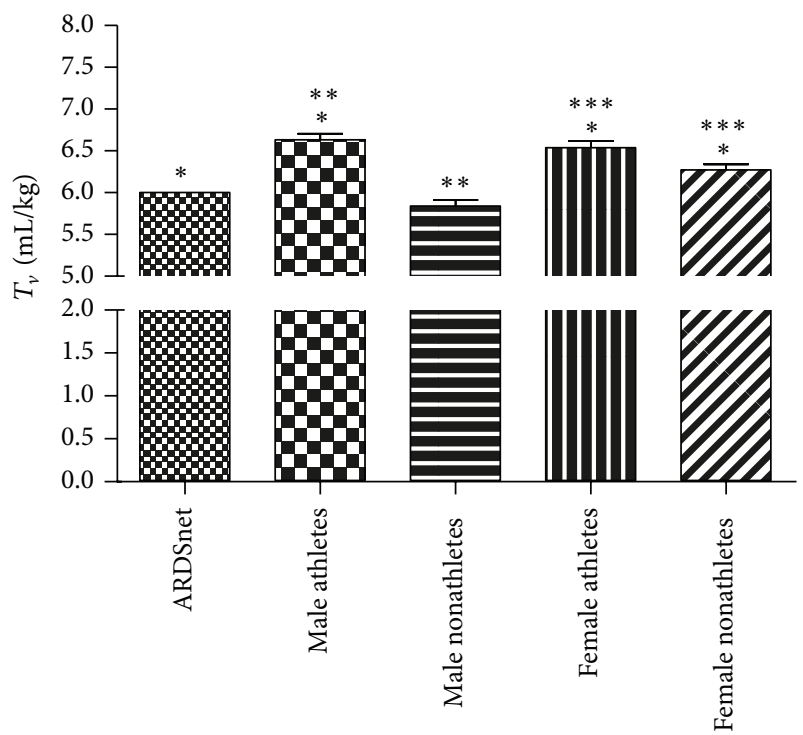

FIGURE 1: Comparison of ARDSnet tidal volume $(6 \mathrm{~mL} / \mathrm{kg})$ to those according to athletic status and sex. ${ }^{*},{ }^{* *}$, and ${ }^{* * *}$ denote statistically significant differences.

protective ventilation according to ARDS Network. This 8.3\% is in accordance with the $8.9 \%$ and $7.8 \%$ higher FVC and $\mathrm{FEV}_{1}$, respectively, found in measured values compared to predicted values as shown in Table 2 .

\section{Discussion}

In this study we found that athletes have significantly higher spirometric values compared to what was predicted and 
TABLE 4: Calculations to extract new $T_{v}\left(T_{v} N\right)$ according to measured (Ms) and predicted (Pr) PFTs.

\begin{tabular}{|c|c|c|c|c|c|c|}
\hline Males & Predicted $(\mathrm{mL})$ & $\% \mathrm{FVCms}$ & $\%$ FVCpr & $\delta(\%)$ & $T_{v} N(\mathrm{~mL})$ & $T_{v} N(\mathrm{~mL} / \mathrm{Kg})$ \\
\hline \multicolumn{7}{|c|}{ Athletes, $n=156$} \\
\hline$T_{v}$ & $454.4 \pm 3.97$ & $7.9 \pm 0.86^{*}$ & $8.6 \pm 0.03^{*}$ & $0.7 \pm 0.08$ & $502.7 \pm 6.9$ & $6.6 \pm 0.07$ \\
\hline \multicolumn{7}{|c|}{ Nonathletes, $n=113$} \\
\hline$T_{v}$ & $438.3 \pm 3.4$ & $9.5 \pm 0.12^{*}$ & $9.1 \pm 0.06^{*}$ & $-0.3 \pm 0.01$ & $426.0 \pm 5.5$ & $5.8 \pm 0.07$ \\
\hline Females & Predicted $(\mathrm{mL})$ & $\% \mathrm{FVCm}$ & \% FVCpr & $\delta(\%)$ & $T_{v} N(\mathrm{~mL})$ & $T_{v} N(\mathrm{~mL} / \mathrm{Kg})$ \\
\hline \multicolumn{7}{|c|}{ Athletes, $n=95$} \\
\hline$T_{v}$ & $375.4 \pm 4.6$ & $8.7 \pm 0.12^{*}$ & $9.4 \pm 0.05^{*}$ & $0.6 \pm 0.01$ & $408.9 \pm 7.1$ & $6.5 \pm 0.08$ \\
\hline \multicolumn{7}{|c|}{ Nonathletes, $n=122$} \\
\hline$T_{v}$ & $319.3 \pm 3.6$ & $9.9 \pm 0.15^{*}$ & $10.3 \pm 0.09^{*}$ & $0.3 \pm 0.01$ & $333.1 \pm 4.9$ & $6.3 \pm 0.07$ \\
\hline
\end{tabular}

FVC: forced vital capacity, Ms: measured, and Pr: predicted. ${ }^{*} P<0.0001,{ }^{* *} P<0.001$.

nonathletes. We also found that tidal volume during mechanical ventilation in athletes should be $6.6 \mathrm{~mL} / \mathrm{kg}$ for males and $6.5 \mathrm{~mL} / \mathrm{kg}$ for females compared to $6 \mathrm{~mL} / \mathrm{kg}$ as suggested by the ARDS Network [1].

Early ventilation strategies in ARDS involved volume controlled ventilation with $T_{v}$ of $10-15 \mathrm{~mL} / \mathrm{kg}$ to achieve "normal" arterial blood gases [11]. However, ventilation itself can cause lung injury and after a landmark study by the ARDS Network a lung protective strategy using $6 \mathrm{~mL} / \mathrm{kg}$ of ideal body weight was established leading to a $9 \%$ absolute mortality reduction along with reduced pulmonary and circulating inflammatory cytokines [1]. This study was confirmed by subsequent study in which patients that were ventilated with higher $T_{v}$ and lower PEEP had increased ICU and hospital mortality [12].

A recent trial in patients with respiratory failure without ARDS also demonstrated low $T_{v}$ ventilation to be protective, preventing ARDS, and associated with a reduction in the release of inflammatory cytokines. This study was stopped early due to an increased incidence of lung injury in patients ventilated with higher $T_{v}[13]$.

Studies addressing several concerns regarding low $T_{v}$ have shown that low $T_{v}$ ventilation is a safe strategy and should be adopted in the management of patients with ARDS [1416]. These studies demonstrate the importance of using lower $T_{v}$ to ventilate the injured lung as opposed to aiming to normalize blood gases variables.

Low $T_{v}$ (lung protective) strategy is a physiological approach using normal tidal volume which is at rest 6$7 \mathrm{~mL} / \mathrm{kg}$ [4]. The ARDS network used this normal $T_{v}$ $(6 \mathrm{~mL} / \mathrm{kg})$ in relation to predicted body weight because normal lung volumes are predicted on the basis of sex and height in an attempt to synchronize $T_{v}$ selection during $\mathrm{MV}$ in ARDS population and normal lung volumes [1].

In this study we compared predicted $T_{v}$ according to ARDS Network calculations to measured and predicted FVC which are normal lung volumes. Our hypothesis was that since normal $T_{v}$ is proportional to normal lung volumes, the comparison of normal $T_{v}$ of $6 \mathrm{~mL} / \mathrm{kg}$ as percentage to actual (measured) FVC could indicate the correct $T_{v}$ appropriate for $\mathrm{MV}$. According to our hypothesis normal $T_{v}$ is a proportion of FVC and thus may be useful in the determination of "normal" $T_{v}$ applied for MV instead of using predicted body weight.
We found also that measured spirometric volumes differ significantly from what was predicted according to athletic status. According to our hypothesis athletes having significantly higher FVC than what was predicted may require higher $T_{v}$ than $6 \mathrm{~mL} / \mathrm{kg}$. We found that $T_{v}$ may differ according to sex and athletics status.

We found that athletes may require an $8-10 \%$ increase in $T_{v}$ that is $6.6 \mathrm{~mL} / \mathrm{kg}$ for males and $6.5 \mathrm{~mL} / \mathrm{kg}$ for females. This difference may result in a $T_{v}$ of $462 \mathrm{~mL}$ instead of $420 \mathrm{~mL}$ for a $70 \mathrm{~kg}$ male athlete ( $42 \mathrm{~mL}$ higher). Also, for the same body weight of $70 \mathrm{Kg}$ female athlete $T_{v}$ would be $455 \mathrm{~mL}$ instead of $420 \mathrm{~mL}$ (35 mL higher).

On the other hand we found that according to measured FVC values nonathlete males may require slightly reduced $T_{v}$ of $5.8 \mathrm{~mL} / \mathrm{kg}$ and females of $6.3 \mathrm{~mL} / \mathrm{kg}$. This difference may result in a $T_{v}$ of $406 \mathrm{~mL}$ instead of $420 \mathrm{~mL}$ for a $70 \mathrm{Kg}$ male nonathlete (14 mL lower) and $441 \mathrm{~mL}$ instead of $420 \mathrm{~mL}$ for a female athlete ( $21 \mathrm{~mL}$ higher). Thus, it can be argued that for nonathletes the approach of $6 \mathrm{~mL} / \mathrm{kg}$ is appropriate with a range of $5.8-6.3 \mathrm{~mL} / \mathrm{kg}$.

Comparing males there is a significant difference between athletes and nonathletes of $0.8 \mathrm{~mL} / \mathrm{kg}(6.6-5.8)$. That is for a $70 \mathrm{~kg}$ male athlete a $T_{v}$ of $462 \mathrm{~mL}$ is required and for a male nonathlete a $T_{v}$ of $406 \mathrm{~mL}$ is required $(\delta=56 \mathrm{~mL})$. For females this difference is lower being $0.2 \mathrm{~mL} / \mathrm{kg}(6.5-6.3)$ and of a female athlete the $T_{v}$ would be $455 \mathrm{~mL}$ while for a female nonathlete the $T_{v}$ would be $441 \mathrm{~mL}(\delta=14 \mathrm{~mL})$.

In accordance with our study it was found larger lung capacity ( $\mathrm{FVC}$ and $\mathrm{FEV}_{1}$ ) independent of age and height in never smokers with higher levels of physical exercise [17]. There also is evidence that even mild but also professional exercise is related to higher spirometric values and lower $\mathrm{FEV}_{1}$ loss over time [18-23]. These studies are in accordance with our findings that athletes have higher spirometric values to predicted [24].

It should be mentioned that currently in Europe, the reference equations for spirometry published by ECSC statement are used for people aged 18-70 yrs, with a height range of $155-195 \mathrm{~cm}$ in males and $145-180 \mathrm{~cm}$ in females [10]. The recent ATS/ERS Task Force committee does not recommend any specific set of equations for use in Europe but suggests the need for a new Europe-wide study to derive updated reference equations for lung function [8]. Also, suggests that 
the subjects being tested should be asked to identify their own race/ethnic group and even nation and recognises and encourages the continuing interest of worldwide researchers in deriving and using race/ethnic/nation-specific reference equations [8]. Finally, there are unexplained differences in lung function between ethnically similar nonsmoking symptom-free populations and centre variation between several European countries was found more likely to be due to true population differences [25]. This is in accordance with previous observations by us [26]. These issues have been recently addressed by the European Respiratory Society Global Lung Function Initiative research examining over 97,759 records of healthy nonsmokers aged 2.5-95 yrs [27].

Some limitations of our study should be underscored. Firstly, this is a hypothetical study based on our data that normal spirometric lung volumes differ among athletes and nonathletes and that athletes may require higher $T_{v}$. There are no supporting data in the literature suggesting that the increase in $T_{v}$ is related to the increase in FVC. Also, this was not a controlled clinical trial but an observational study. Most of our healthy adult participants were from mid to upper socioeconomic strata, so generalizing to other groups (especially to clinical populations such as patients with respiratory disease) is not advised. Also, we examined different sports and ages with different exercise duration and intensity. Finally $T_{v}$ was measured during spirometry and thus calculated tidal volumes were not compared to what was calculated.

\section{Conclusions}

Professional athletes have significantly higher spirometric lung volumes compared to currently predicted values and those of nonathletes. According to measured FVC values of our population and our hypothesis, appropriate $T_{v}$ may differ between athletes and nonathletes and could be $10 \%$ higher compared to ARDSnet recommendation. Additional $T_{v}$ for professional athletes under mechanical ventilation and ARDS may be $0.6 \mathrm{~mL} / \mathrm{kg}$ for males and $0.5 \mathrm{~mL} / \mathrm{kg}$ for females. The tidal volume increase may be proportional to the percentage of FVC increase compared to predicted values. For nonathletes the ARDSnet recommendation maybe appropriate. Our findings need to be further investigated and tested.

$\begin{array}{ll}\text { Abbreviations } \\ \text { PFTs: } & \text { Pulmonary Function Tests } \\ \text { FVC: } & \text { Forced Vital Capacity } \\ \text { FEV }_{1}: & \text { Forced Expiratory Volume in One Second } \\ \text { ALI/ARDS: } & \text { Acute Lung Injury/Acute Respiratory } \\ & \text { Distress Syndrome } \\ \text { ATS/ERS: } & \text { American Thoracic Society/European } \\ & \text { Respiratory Society } \\ \text { BMI: } & \text { Body Mass Index } \\ \text { BSA: } & \text { Body Surface Area } \\ \text { ECCS: } & \text { European Community for Steel and Coal. }\end{array}$

\section{Ethical Approval}

The research protocol was evaluated and approved by the local Institutional Review Board.

\section{Conflict of Interests}

The author declares that he has no conflict of interests.

\section{Authors' Contributions}

The idea for the study belongs to P. Myrianthefs and G. Baltopoulos. The study was implemented and data was collected by P. Myrianthefs. The analysis of the data was performed by P. Myrianthefs. P. Myrianthefs wrote the first draft of the paper and then G. Baltopoulos read and approved the final version of the paper.

\section{Acknowledgments}

The study was partially funded by OPAP (Greek Organization of Football Prognostics). The study sponsors had no involvement in the study design, in the collection, analysis, and interpretation of the data; in the writing of the paper; and in the decision to submit the paper for publication.

\section{References}

[1] The Acute Respiratory Distress Syndrome Network, "Ventilation with lower tidal volumes as compared with traditional tidal volumes for acute lung injury and the acute respiratory distress syndrome," The New England Journal of Medicine, vol. 342, no. 18, pp. 1301-1308, 2000.

[2] R. O. Crapo, A. H. Morris, and R. M. Gardner, "Reference spirometric values using techniques and equipment that meet ATS recommendations," American Review of Respiratory Disease, vol. 123, no. 6, pp. 659-664, 1981.

[3] R. O. Crapo, A. H. Morris, P. D. Clayton, and C. R. Nixon, "Lung volumes in healthy nonsmoking adults," Clinical Respiratory Physiology, vol. 18, no. 3, pp. 419-425, 1982.

[4] S. M. Tenney and J. E. Remmers, "Comparative quantitative morphology of the mammalian lung: Diffusing area," Nature, vol. 197, no. 4862, pp. 54-56, 1963.

[5] M. R. Miller, R. Crapo, J. Hankinson et al., "General considerations for lung function testing," European Respiratory Journal, vol. 26, no. 1, pp. 153-161, 2005.

[6] American Thoracic Society, "Standardization of spirometry," American Journal of Respiratory and Critical Care Medicine, vol. 152, pp. 1107-1136, 1995.

[7] M. R. Miller, J. Hankinson, V. Brusasco et al., "ATS/ERS task force: standardization of spirometry," European Respiratory Journal, vol. 26, pp. 319-338, 2005.

[8] R. Pellegrino, G. Viegi, V. Brusasco et al., "Interpretative strategies for lung function tests," European Respiratory Journal, vol. 26, no. 5, pp. 948-968, 2005.

[9] J. E. Knoben and P. O. Anderson, Eds., Handbook of Clinical Drug Data, Drug Intelligence, Hamilton, Ill, USA, 7th edition, 1993.

[10] P. H. Quanjer, G. J. Tammeling, J. E. Cotes, O. F. Pedersen, R. Peslin, and J. C. Yernault, "Lung volumes and forced ventilatory 
flows. Report Working Party Standardization of Lung Function Tests, European Community for Steel and Coal. Official Statement of the European Respiratory Society," The European Respiratory Journal, vol. 16, pp. S5-S40, 1993.

[11] A. Dushianthan, M. P. W. Grocott, A. D. Postle, and R. Cusack, "Acute respiratory distress syndrome and acute lung injury," Postgraduate Medical Journal, vol. 87, no. 1031, pp. 612-622, 2011.

[12] J. Villar, R. M. Kacmarek, L. Pérez-Méndez, and A. AguirreJaime, "A high positive end-expiratory pressure, low tidal volume ventilatory strategy improves outcome in persistent acute respiratory distress syndrome: a randomized, controlled trial," Critical Care Medicine, vol. 34, no. 5, pp. 1311-1318, 2006.

[13] R. M. Determann, A. Royakkers, E. K. Wolthuis et al., "Ventilation with lower tidal volumes as compared with conventional tidal volumes for patients without acute lung injury: a preventive randomized controlled trial," Critical Care, vol. 14, no. 1, article R1, 2010.

[14] G. D. Rubenfeld, C. Cooper, G. Carter, B. T. Thompson, and L. D. Hudson, "Barriers to providing lung-protective ventilation to patients with acute lung injury," Critical Care Medicine, vol. 32, no. 6, pp. 1289-1293, 2004.

[15] I. W. Cheng, M. D. Eisner, B. T. Thompson, L. B. Ware, and M. A. Matthay, "Acute effects of tidal volume strategy on hemodynamics, fluid balance, and sedation in acute lung injury," Critical Care Medicine, vol. 33, no. 1, pp. 63-70, 2005.

[16] J. M. Kahn, L. Andersson, V. Karir, N. L. Polissar, M. J. Neff, and G. D. Rubenfeld, "Low tidal volume ventilation does not increase sedation use in patients with acute lung injury," Critical Care Medicine, vol. 33, no. 4, pp. 766-771, 2005.

[17] T. L. Holmen, E. Barrett-Connor, J. Clausen, J. Holmen, and L. Bjermer, "Physical exercise, sports, and lung function in smoking versus nonsmoking adolescents," European Respiratory Journal, vol. 19, no. 1, pp. 8-15, 2002.

[18] Y. J. Cheng, C. A. Macera, C. L. Addy, F. S. Sy, D. Wieland, and S. N. Blair, "Effects of physical activity on exercise tests and respiratory function," British Journal of Sports Medicine, vol. 37, no. 6, pp. 521-528, 2003.

[19] M. Doherty, "Comparison of lung volume in Greek swimmers, land based athletes, and sedentary controls using allometric scaling," British Journal of Sports Medicine, vol. 31, no. 4, pp. 337341, 1997.

[20] P. K. Mehrotra, N. Varma, S. Tiwari, and P. Kumar, "Pulmonary functions in Indian sportsmen playing different sports," Indian Journal of Physiology and Pharmacology, vol. 42, no. 3, pp. 412416, 1998.

[21] R. W. Jakes, N. E. Day, B. Patel et al., "Physical inactivity is associated with lower forced expiratory volume in 1 second: European prospective investigation into cancer-norfolk prospective population study," American Journal of Epidemiology, vol. 156, no. 2, pp. 139-147, 2002.

[22] N. Galanis, D. Farmakiotis, K. Kouraki, and A. Fachadidou, "Forced expiratory volume in one second and peak expiratory flow rate values in non-professional male tennis players," Journal of Sports Medicine and Physical Fitness, vol. 46, no. 1, pp. 128-131, 2006.

[23] D. MacAuley, E. McCrum, A. Evans, G. Stott, C. Boreham, and T. Trinick, "Physical activity, physical fitness and respiratory function-exercise and respiratory function," Irish Journal of Medical Science, vol. 168, no. 2, pp. 119-123, 1999.

[24] P. Myrianthefs, A. Gavala, E. Skordilis et al., "Spirometric reference values from a sample of an urban Greek population," Respiratory Therapy, no. 5, pp. 36-41, 2010.
[25] S. Chinn, D. Jarvis, C. Svanes, and P. Burney, "Sources of variation in forced expiratory volume in one second and forced vital capacity," European Respiratory Journal, vol. 27, no. 4, pp. 767-773, 2006.

[26] G. Baltopoulos, G. Fildisis, S. Karatzas, F. Georgiakodis, and P. Myrianthefs, "Reference values and prediction equations for FVC and FEV1 in the Greek elderly," Lung, vol. 178, no. 4, pp. 201-212, 2000.

[27] P. H. Quanjer, S. Stanojevic, and T. J. Cole, “The ERS Global Lung Function Initiative Multi-ethnic reference values for spirometry for the 3-95-yr age range: the global lung function 2012 equations," European Respiratory Journal, vol. 40, no. 6, pp. 1324-1343, 2012. 


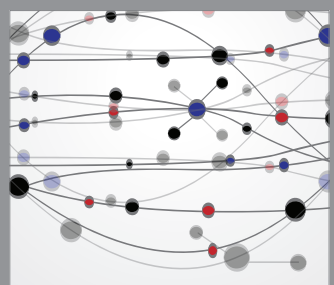

The Scientific World Journal
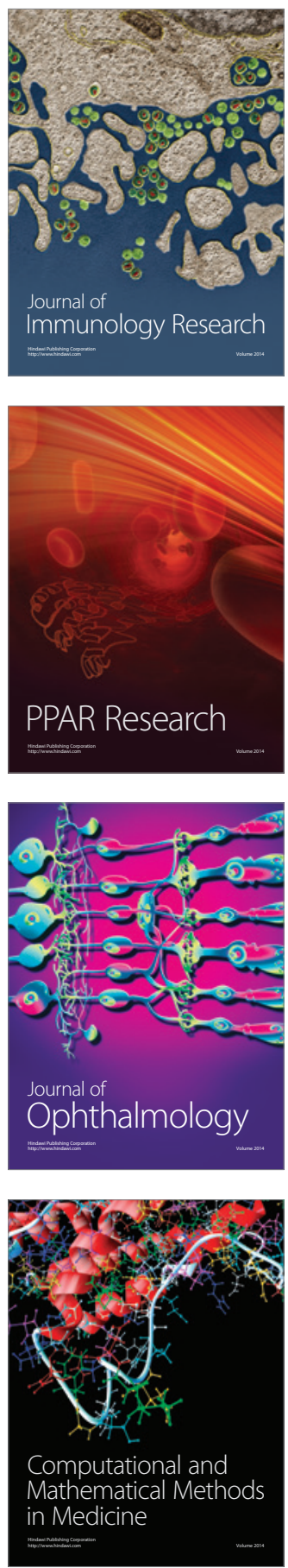

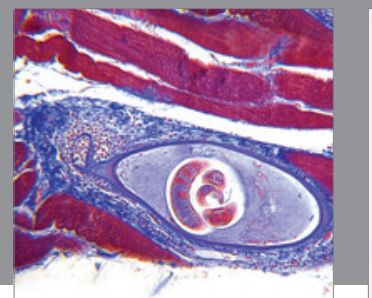

Gastroenterology

Research and Practice
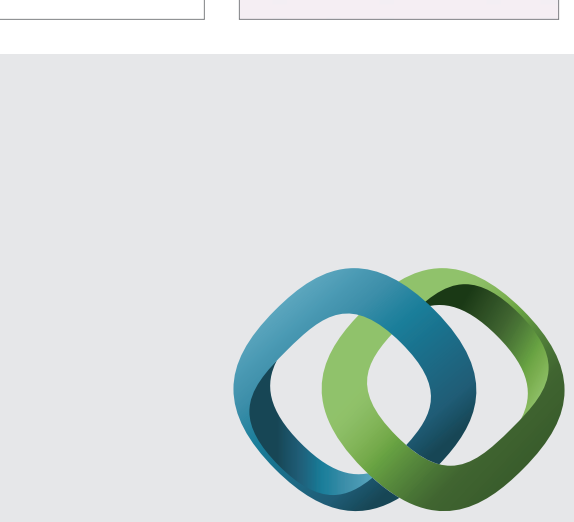

\section{Hindawi}

Submit your manuscripts at

http://www.hindawi.com
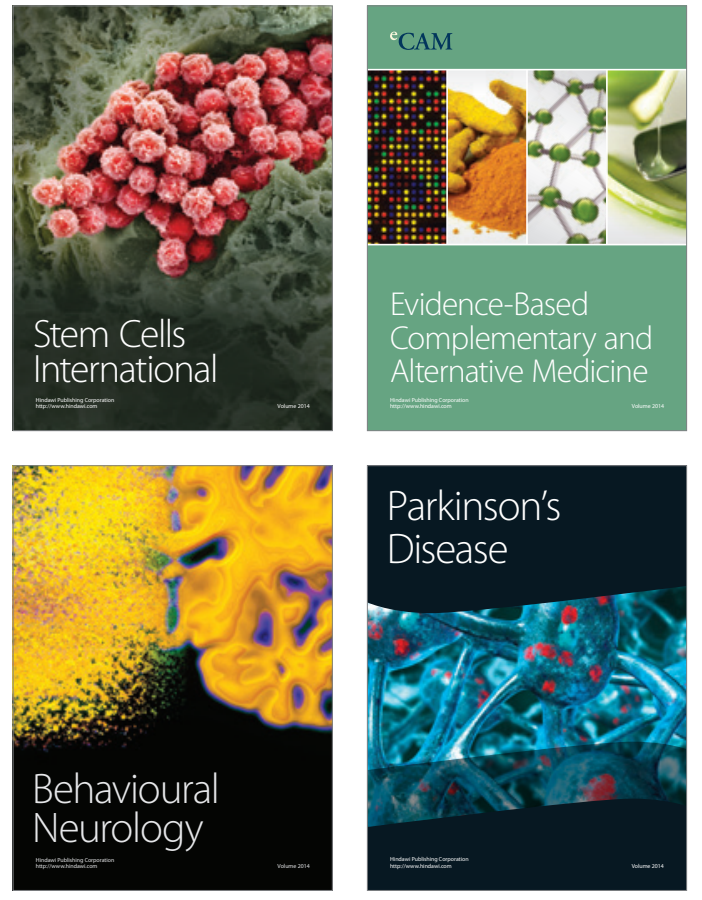
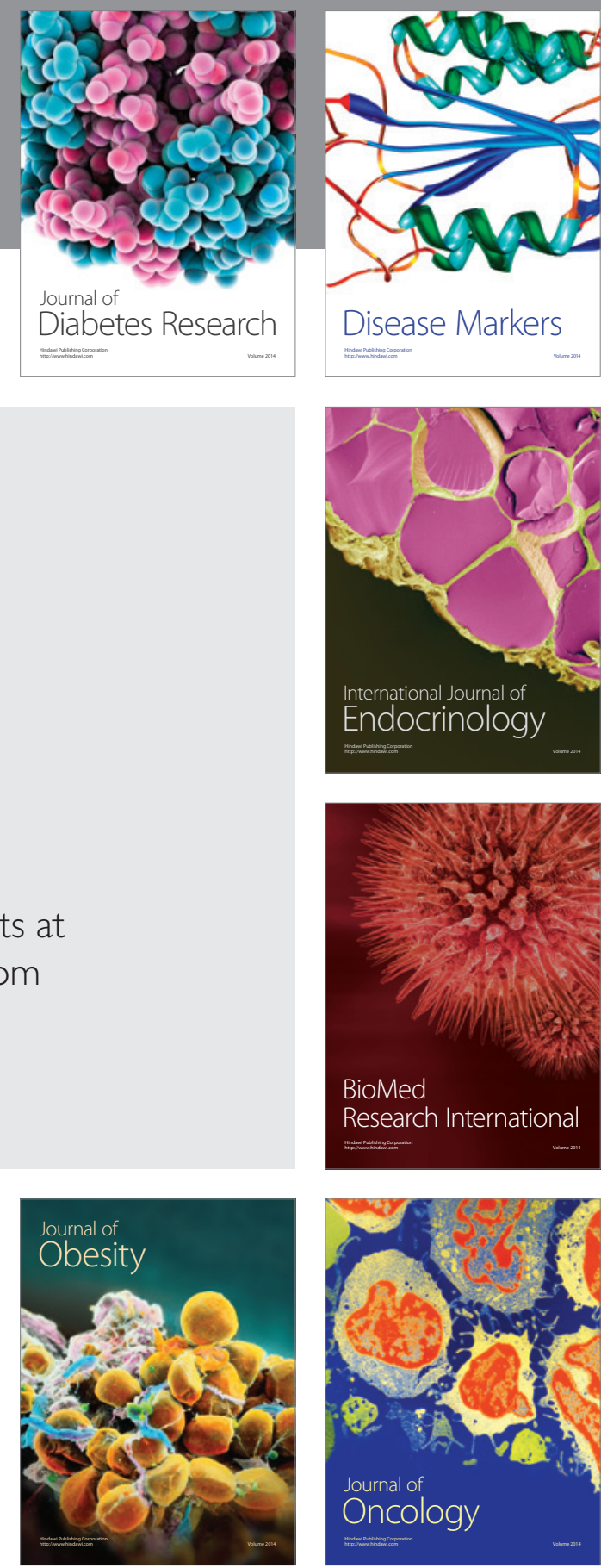

Disease Markers
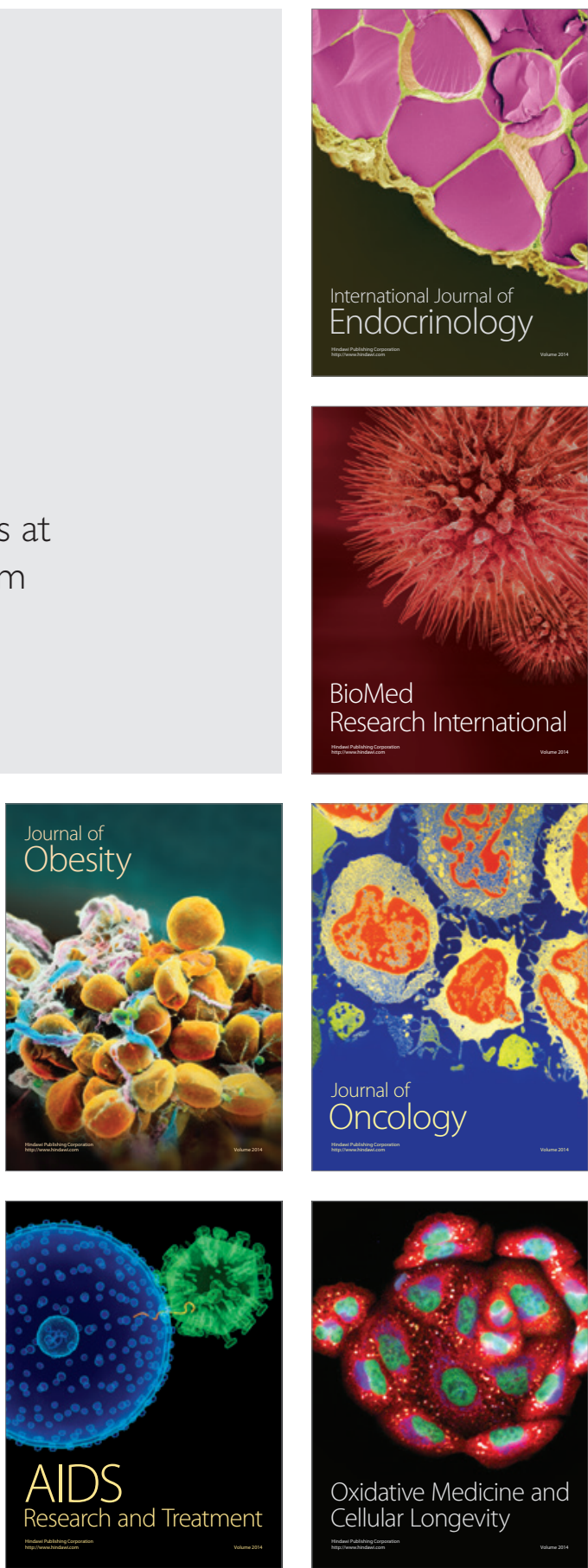